\title{
Ipanema e suas modas: passado $x$ presente
}

\section{Marisol Rodriguez Valle}

Mestre em Sociologia e Antropologia pelo PPGSA/IFCS/UFRJ.

Artigo aceito para publicação em 22/09/05

\begin{abstract}
resumo $\mathrm{O}$ objetivo deste artigo é analisar a contruçâo social do bairro de Ipanema nos meios de comunicação. Realizo uma análise aprofundada de três livros e três suplementos de imprensa e estabeleço uma comparação entre as representações sobre o passado e o presente do bairro. Verifico os espaços, as personalidades, as visóes de mundo e os estilos de vida que caracterizam a Ipanema de hoje e de ontem.
\end{abstract}

palavras-chave representaçôes, bairro, espaços urbanos e estilo de vida.

\section{A província da ousadia}

Responder à pergunta "onde você mora?" pode ser constrangedor para muitos cariocas. A simples mençáo ao nome do bairro é capaz de suscitar um conjunto de idéias sobre seu morador. Quando a resposta é "Ipanema", algumas reações como "que chique!" ou expressóes faciais como a de levantar a sobrancelha revelam que existe um determinado imaginário sobre esse bairro. Experiências como essas fazem com que, em determinadas circunstâncias, eu evite dizer onde moro ou sinta vergonha de minha resposta.

No meu caso, o constrangimento se agrava por não me perceber como alguém que corresponda aos quesitos "típicos" do morador de meu bairro. Morar em Ipanema sempre significou, sob meu ponto de vista, ter de sacrificar certas comodidades para poder pagar elevadas abstract The objective of this article is to analyze the social construction of the quarter of Ipanema in the media. I carry trough a comment on three books and three supplements of the press and establish a comparison between the representations of the past and the present of the quarter. I verify the spaces, the personalities, the world visions and the life style that characterize Ipanema of before and today.

keywords representations, neighborhood, urban spaces, life style.

taxas de aluguel, condomínio e impostos. Muitas vezes me percebo como "peixe fora d'água" nesse bairro, sobretudo ao constatar o elevado padráo de vida dos vizinhos ou quando passo em frente às vitrines das luxuosas grifes que se encontram nos arredores. Há, contudo, um aspecto simbólico muito forte em "morar em Ipanema”, e a força desse simbolismo se traduz nas práticas e nos projetos dos indivíduos, como foi o caso da escolha de minha mãe por morar ali apesar das conseqüências que essa decisão sempre acarretou. Em grande número de sociedades urbanas, e de forma muito marcante no Rio de Janeiro, o espaço constitui elemento importante para a definição do status dos indivíduos. Há, nessa cidade, uma nítida hierarquia de bairros e, através desta, os indivíduos percebem a sociedade e se situam dentro dela (Velho 1978). 
Estranhar o bairro em que se vive pode se converter em uma experiência bastante significativa, principalmente para quem pretende exercitar uma visão antropológica sobre o próprio meio social. Proporciona, talvez, uma maior facilidade para "transformar o familiar em exótico", como sugere Da Matta (1978). Este exercício reflexivo que pratico cotidianamente no bairro onde moro fez com que Ipanema se tornasse, para mim, além de um local intrigante, um objeto a ser pesquisado.

Uma vez decidida a realizar uma investigação sobre Ipanema, iniciei uma busca por referências bibliográficas sobre o local. Deparei-me com livros que continham descrições, fotos e comentários que em nada se assemelhavam ao que costumo observar no bairro. A Rua Garcia D'Ávila, por exemplo, que me surpreende às vésperas do Natal com seu tapete vermelho estendido na calçada de lojas como Louis Vuitton, Cartier, Mont Blanc e H. Stern, não ocupava uma página sequer de tais livros. Aquelas evidências que para mim atestam que Ipanema é uma das localidades mais caras do Rio de Janeiro passavam quase despercebidas nessas obras sobre o bairro. O que encontrei foi uma certa regularidade no modo como os autores retratam Ipanema, como por exemplo, através de uma referência constante a épocas passadas. A Ipanema dos livros é uma Ipanema "de memórias", aparecendo como um local que vivenciou grandes mudanças comportamentais, artísticas e culturais nas décadas de 1960 e 1970.

Enquanto era transportada para uma Ipanema por mim desconhecida - um bairro "provinciano", "boêmio" e "libertário" - os jornais e revistas de grande circulação no Rio de Janeiro celebravam os 110 anos de uma Ipanema "moderna", "luxuosa" e "cosmopolita”. Notei, portanto, o caráter subjetivo e simbólico das informaçóes contidas nos meios de comunicação. Mais do que apresentar fatos sobre Ipanema, os livros e a imprensa contêm versóes que produzem e reproduzem concepções específicas sobre esse bairro. Foi a partir dessa percepçáo que o material no qual esperava obter informaçóes "documentais" e “objetivas" se transformou em um objeto de reflexão para minha pesquisa.

Neste trabalho realizo uma análise sobre os meios de comunicaçáo para compreender o modo como Ipanema é percebida, elaborada e divulgada. ${ }^{1}$ Busco examinar os valores, símbolos e noçóes que constroem o passado e o presente do bairro comparando os diferentes espaços, personalidades e características que representam a Ipanema de ontem e a de hoje. Considerando que "Ipanema", mais do que um espaço físico delimitado, exprime um conjunto de crenças e de representações culturalmente elaboradas, busco analisar o processo de construção social de um bairro emblemático da cidade do Rio de Janeiro.

\section{Um bairro carioca}

Ipanema possui 1,67 quilômetro quadrado. Seu território consiste em uma estreita faixa de terra, de formato quase retangular, banhada ao sul pelo oceano Atlântico e ao norte pela Lagoa Rodrigo de Freitas. Em comparação com a maioria dos bairros do Rio de Janeiro, Ipanema pode

1. Os livros que constituem o material do trabalho são: Ela é carioca (1999), de Ruy Castro; Ipanema, se não me falha a memória (2000) de Jaguar e Os degraus de Ipanema (1997), de Carlos Leonam. Dentre as matérias publicadas na imprensa no ano de 2004, estipulei como critério de seleção aquelas dedicadas ao aniversário de 110 anos do bairro de Ipanema. Utilizei como objeto de reflexão suplementos dos jornais O Globo, Jornal do Brasil e da revista semanal Veja Rio que apresentavam "Ipanema” estampada em suas capas. Trata-se, respectivamente de Caderno Zona Sul - "Ipanema, 110 anos na vanguarda" ( $O$ Globo, 22.abr.2004); Caderno H - "O garotão de Ipanema - Ipanema 110 anos, edição especial” (Jornal do Brasil, 25.abr.2004) e "Ipanema 110 anos: Histórias e personagens do bairro mais charmoso da cidade" (Veja Rio 26.abr.2004-02.maio. 2004). 
ser classificada como pequena, no entanto, suas dimensóes espaciais não são proporcionais às simbólicas: Ipanema é entendida como um emblema de sua cidade e até mesmo de seu país.

Essa representaçáo aparece de diversas maneiras no material selecionado para este estudo, como por exemplo, através das noçóes de "moda", "capital cultural", "boemia" e "estilo de vida": "Ipanema está para o Rio como Paris para o mundo. É sinônimo de moda. Tudo o que a menina de Ipanema usa a caminho do mar, da universidade, das compras, as meninas de todo o Brasil copiam" (Jornal do Brasil: 8); "o bairro era a capital cultural do Rio, e portanto, a capital cultural do Brasil" (O Globo: 34); "Talvez seja impossível definir o carioca sem o espaço informal de cordialidade... Em Ipanema, como bairro carioquíssimo que é, não podia faltar botequim" (Jornal do Brasil: 14) e "Ipanema traduz um estilo de vida bem carioca: praia, calçadão e espontaneidade" ( $O$ Globo: 16).

O livro de Ruy Castro sobre Ipanema expressa as mesmas idéias encontradas na imprensa. O título Ela é carioca sugere que o bairro náo poderia estar localizado em outra cidade que não fosse o Rio de Janeiro. Em abril deste ano, esse escritor foi convocado por uma livraria para tratar o aniversário de 110 anos do bairro. Em suas primeiras palavras, Ruy Castro sugeriu que Ipanema é um bairro típico do Rio através da oposição "formalidade $x$ informalidade" que comumente se estabelece entre paulistas e cariocas. $\mathrm{O}$ autor negou que naquela ocasiáo faria uma "palestra com viés acadêmico", pois "isso só seria possível se Ipanema fosse em São Paulo", e preferiu denominar de "bate-papo" a sua participação na homenagem ao bairro.

A importância de um projeto de preservaçáo cultural para o bairro de Ipanema fundamenta-se no decreto publicado em julho de 2003, no Diário Oficial da Prefeitura do Rio de Janeiro, por meio de consideraçóes como estas: “...Ipanema, pela sua história, tornou-se uma referência do modo de vida do carioca, refletindo-se em todo o país". O depoimento do Secretário Municipal das Culturas também dissemina a mesma idéia: "Pela peculiaridade de Ipanema náo poderíamos tombar apenas imóveis. Ipanema resume bem o espírito do carioca, seu comportamento, suas atitudes. E é isso que estamos preservando também" (O Globo 20.jul.2003).

Ao considerar a relação metonímica que se estabelece entre bairro, cidade e país, podese pensar que as representaçóes sobre Ipanema apresentam dimensóes mais amplas do que as de um simples bairro e se estendem a um imaginário sobre "ser carioca" e "ser brasileiro". Apesar disso, os elementos que estabelecem a ligação entre o ipanemense, o carioca e o brasileiro, como os conceitos de moda, boemia e estilo de vida, são tratados aqui como típicos de Ipanema. É preciso ter em mente, contudo, que essa simbologia é capaz de transcender os limites territoriais de 1,67 quilômetro quadrado desse lugar.

\section{A Ipanema do passado}

Nos suplementos de imprensa pesquisados, a idéia de moda é recorrentemente utilizada para designar o passado de Ipanema: "Nos anos 60 e 70, Ipanema viveu uma espécie de fase áurea, exportando personagens, moda, artistas, posicionamentos políticos e modos de vida" (Jornal do Brasil: 4). O bairro é qualificado como "Laboratório de moda... centro irradiador de tendências" (O Globo:18) ou "Lugar onde não faltaram musas, modismos, acontecimentos e polêmica" (Veja Rio: 12). Nos livros, a idéia também é freqüente. Jaguar acredita que o bairro "se intrometia na cidade e no estado, ditava moda, hábitos e costumes para o Brasil e o mundo; cagava regras" (: 12).

A concepção de moda utilizada para qualificar Ipanema não se relaciona somente ao sentido mais comum de inovaçóes nas vestimentas ou nos acessórios de uso pessoal; envolve também outros significados. A associação 
entre Ipanema e moda fundamenta-se na idéia de que os ipanemenses do passado tinham uma habilidade peculiar de transgredir, criar e inventar estilos de vida, comportamentos e atitudes. Para ilustrar esta idéia não é preciso ler os livros ou as matérias de jornais e revistas que falam sobre o bairro, bastando observar as fotografias que se repetem nesse material.

A praia serve como o cenário privilegiado das imagens mais emblemáticas do passado de Ipanema, como a da atriz Leila Diniz grávida de biquíni; a do ex-guerrilheiro Fernando Gabeira de "tanga" tomando uma limonada ou a de um grupo de mulheres com os seios à mostra, rodeadas de repórteres e de curiosos. Ipanema teria sido, sob esse ponto de vista, um local pioneiro, onde nasceram costumes e comportamentos que romperam com padróes tradicionais de conduta. De acordo com os livros e o material de imprensa, as atitudes ipanemenses teriam sido posteriormente difundidas e até copiadas em outros locais do Rio de Janeiro e do Brasil.

A barriga grávida de uma personalidade pública, o "topless" feminino e a semi-nudez de um militante de esquerda são imagens estrategicamente utilizadas para tornar concretas as idéias de "moda", "inovação" e "ousadia" que também contribuem para o imaginário que associa Ipanema ao conceito de "vanguarda". Percebe-se que essas fotos não são selecionadas arbitrariamente, já que são justamente aquelas em que a "transgressão" está mais evidente por recair no próprio corpo das personalidades fotografadas.

A partir da pesquisa de Velho (1998) sobre jovens da década de 1970, nota-se que a idéia de ser "vanguarda" aparece como um valor fundamental para as camadas médias da zona sul do Rio de Janeiro nessa década. Esse grupo apresentaria forte anseio por mostrar um estilo de vida "vanguardista", que se traduziria no valor atribuído ao tema da mudança como um modo de se opor a uma visão de mundo tradicional e conservadora:
O grupo definia-se como sendo orientado para a mudança. $\mathrm{O}$ vanguardismo implica na inovação, na invenção... ser um artista de vanguarda, por exemplo, implicaria não ser pessoalmente "quadrado", "careta”, "pequeno-burguês". Mesmo as pessoas que não desempenhavam uma atividade que náo fosse considerada especialmente inovadora ou vanguardista aceitavam, em princípio, a importância de ser "aberto", rejeitando as escalas de valores das famílias de origem, consideradas hipócritas, repressivas etc. (: 63-64).

Se Ipanema é entendida como um bairro onde se desenvolveram comportamentos "vanguardistas", é no espaço da praia - mais propício para a exposição corporal - que as novas moralidades de Ipanema ganharam um destaque público. A partir da análise de Goldenberg (1995) sobre a trajetória da atriz Leila Diniz, pode-se argumentar que é na praia que o corpo ipanemense aparece sob sua forma "transgressora", "polêmica" ou "libertária". Lembrando que na década de 1970 as mulheres grávidas evitavam freqüentar espaços como a praia ou procuravam disfarçar suas barrigas com trajes de banho apropriados, Goldenberg (1995) sustenta que a barriga grávida de Leila Diniz, tornada pública em 1971, materializou e corporificou seus comportamentos transgressores. "A barriga grávida de Leila Diniz, exibida de biquíni nas praias de Ipanema, é ainda hoje lembrada como símbolo da liberação da mulher no Brasil...” (: 208-209).

Para compreender a crença de que Ipanema "lançou modas" é preciso atentar para o destaque atribuído às personalidades desse bairro. $\mathrm{O}$ material pesquisado sugere que falar de Ipanema não significa apenas descrever um espaço geográfico delimitado, mas principalmente, lembrar de indivíduos "ousados", “irreverentes" e "polêmicos". O bairro recebe as mesmas qualificações que são atribuídas aos seus freqüentadores e habitantes, o que faz pensar em uma espécie de "contágio" que se estabelece 
entre o espaço e os indivíduos e vice-versa. $\mathrm{O}$ ipanemense teria a capacidade de "contagiar" o bairro, ao mesmo tempo em que é contagiado pelas características desse espaço.

A imprensa endossa esta associaçáo entre Ipanema e suas personalidades quando se refere ao "bairro de Tom e Vinícius", "da Garota de Ipanema" e divulga as fotos da tanga de Gabeira e da gravidez de Leila Diniz. O formato de Ela é carioca - que se apresenta sob a proposta de uma enciclopédia - também induz à idéia de que cada indivíduo retratado na obra é portador de uma definição particular. A descrição dos comportamentos, manias, gostos, preferências e vontades de cada ipanemense, demonstra uma valorização das escolhas individuais e enfatiza o caráter autônomo de um grupo social, sobretudo de jovens de classes médias, que vivenciavam de modo pioneiro no Brasil, um processo de socialização marcadamente individualista. Ruy Castro salienta, ainda, que a experiência com a prática psicanalítica tornou-se recorrente entre aqueles jovens de Ipanema na década de 1970.

Náo seria incorreto afirmar que é apenas em sociedades que tomam o indivíduo como um valor moral que a moda poderia despontar como um tema possível para análise acadêmica. A maneira como a maioria dos filósofos, sociólogos e historiadores concebem o fenômeno - por meio de mecanismos constantes de imitação e de distinção - revela a tensão do indivíduo moderno ocidental que oscila entre o desejo de receber apoio e aceitação de grupos sociais e as exigências internas e externas por criar os contornos de uma individualidade singular. Esse "dualismo de nossa existência", como se refere Simmel (1988), auxilia o entendimento das sociedades metropolitanas e individualistas colaborando também para a compreensão da associação entre Ipanema e a idéia de moda.

Sem deixar de lembrar que o foco desta pesquisa é um bairro e, portanto, uma estrutura física delimitada, é interessante observar que as representaçóes elaboradas pelos livros e pela imprensa recaem, muitas vezes, sobre espaços específicos de Ipanema. Nem todas as ruas, casas e esquinas recebem as mesmas qualificaçóes que são atribuídas ao bairro como um todo. Existem localidades que recebem maior destaque por “assumirem” o "espírito ipanemense". É evidente que os espaços emblemáticos do passado são precisamente aqueles onde os indivíduos "criativos" e "que lançam modas" se encontravam.

Além da praia, antigos botequins são lembrados como locais da "efervescência" cultural ipanemense da década de 1960. No livro de Ruy Castro, os botecos e "pés-sujos" ocupam oito verbetes da enciclopédia: Bar Lagoa, Bofetada, Calypso, Jangadeiro, Mau Cheiro, Varanda, Veloso e Zeppelin. Na imprensa, esses locais aparecem como os principais pontos de encontro de artistas brasileiros, como os músicos da Bossa Nova e os cineastas do Cinema Novo. O Caderno Zona Sul do Jornal O Globo diz que os artistas cariocas da década de 1960 "fizeram nascer uma nova Ipanema a partir dos movimentos nascidos em mesas de bar. Crias dessa geração foram a Bossa Nova e o Cinema Novo" (: 35). A imprensa especifica cada bar ipanemense segundo seu tipo de público: "Escritores e jornalistas reuniam-se no Zeppelin... músicos no Veloso... Havia também o Jangadeiro, reduto da Banda de Ipanema... e o pé-sujo Mau Cheiro freqüentado pelo pessoal do Cinema Novo" (Veja Rio: 14).

Assim como o Mau Cheiro é pensado como o "pé-sujo" do "pessoal do Cinema Novo", os músicos da Bossa Nova são recordados por freqüentar, principalmente, o Bar Veloso. O significado do Veloso como um dos espaços que associam a Bossa Nova ao bairro de Ipanema relaciona-se, em primeiro lugar, à criação de "Garota de Ipanema”, a música mais famosa desse estilo musical. Em decorrência do grande êxito alcançado por Garota de Ipanema no Brasil e no exterior - a canção está entre as 
mais executadas do mundo - a história da criação dessa música, que envolve os compositores Tom Jobim e Vinícius de Moraes, a musa inspiradora Helô Pinheiro e o bar Veloso, transformou-se em uma lenda do bairro, narrada por todas as matérias analisadas:

Nenhuma canção nacional foi - e continua sendo - tão executada quanto "Garota de Ipanema”.... A música de Tom e Vinícius, de 1962, foi inspirada em Helô Pinheiro quando passava a caminho do mar em frente ao bar Veloso - hoje Garota de Ipanema (O Globo: 38).

Uma das mais executadas cançóes do mundo foi composta em 1962, na casa de Tom Jobim. A idéia nasceu nas mesas do bar Veloso, onde Tom e Vinícius passavam horas bebericando, jogando conversa fora e observando as mulheres, entre elas a musa Helô Pinheiro (Veja Rio: 14).

A ligação entre o Cinema Novo e a Bossa Nova com o bairro de Ipanema se faz pelo caráter "vanguardista" desses dois movimentos; ambos são entendidos como estilos artísticos que romperam com os padróes estéticos e musicais tradicionais. Todavia, nota-se que o vínculo da Bossa Nova com o bairro aparece de modo ainda mais peculiar se comparado ao do Cinema Novo. Como a própria imprensa menciona, embora a troca de idéias entre os cineastas brasileiros se desenrolasse nos botecos de Ipanema, os filmes desse movimento voltaram-se para cenários nada parecidos com o bairro, como, por exemplo, o sertáo nordestino. No caso da Bossa Nova, Ipanema aparece náo apenas como um ponto de encontro de seus principais representantes, mas figura também como temática de suas cançóes mais famosas.

A construção simbólica de Ipanema como um bairro que "lançou moda" e que se consolidou como vanguarda dos costumes e das manifes- taçóes artísticas brasileiras edifica-se por uma associaçáo entre espaços e pessoas. $\mathrm{O}$ bairro como um todo é tomado por suas partes. A valorização da praia e dos bares demonstra que Ipanema náo era apenas o local onde os indivíduos se encontravam, criavam e executavam os acontecimentos pioneiros. Mais do que isso, o bairro é entendido como um local propício para as inovaçóes por servir de fonte de inspiração e motivo de celebração para os ipanemenses.

O livro de Jaguar fornece outras evidências de que os botequins foram importantes para definir o passado de Ipanema. O autor expressa essa idéia a partir da caracterização dos ipanemenses, narrando histórias bem humoradas ocorridas no espaço dos bares:

Aquela história do coelho no Jangadeiros acho que todo mundo já conhece. Quando um garoto gritou "papai, olha um coelho!" foi um alívio geral. Ninguém ousava dizer que tinha um coelho correndo entre as mesas; pensavam que estavam tendo alucinação alcoólica (: 52).

Entre os "ipanemenhos padróes" descritos no livro de Jaguar, quase todos são apresentados como assíduos freqüentadores de bares e botecos, ou lembrados pelas "loucuras" cometidas em estados alterados de consciência, sob o efeito de bebidas alcoólicas. O próprio autor não se exclui dessa caracterização, desculpando-se, em pelo menos dois trechos do livro, pela sua "amnésia alcoólica" que o fez esquecer de pessoas ou "embaralhar as lembranças". O estilo de vida boêmio do autor e de seus amigos de Ipanema está evidenciado no capítulo dedicado ao "ipanemense ilustre" "Carlinhos de Oli":

Nunca marcamos encontro, mas durante anos a gente se esbarrava na ronda dos bares... chegávamos em horários diferentes mas amiúde éramos os 
últimos a sair. Só íamos embora quando os garçons começavam a jogar baldes d'água nos nossos sapatos. Numa dessas madrugadas, no Degrau, estávamos tomando a saideira em pé porque as cadeiras já estavam empilhadas em cima da mesa. Carlinhos pagou a conta com um cheque que assinou contra a parede. Teve um ataque de fúria quando o cheque foi devolvido; a assinatura "José Carlos de Oli” não conferia. $\mathrm{O}$ "veira” restante estava escrito na parede (: 31-32).

O trecho acima poderia representar uma descontinuidade nas representaçóes sobre o bairro de Ipanema, já que o bar mencionado localiza-se no Leblon. Contudo, Jaguar insiste que, embora o seu grupo freqüentasse outros locais da cidade, inclusive os bares da Lapa, Leblon e Copacabana, o "clima" que emprestavam a esses ambientes era marcadamente "ipanemense":

As festas que Albino e eu dávamos na Estudantina Musical, na praça Tiradentes, no Silvestre, em Santa Teresa, no Elite, na Praça da República, e na Banda Portugal, na Presidente Vargas, eram festas ipanemenses... A turma de Ipanema aprontava no Degrau (Leblon)... no Alfredão (Lido), no Bar Brasil (Lapa), na Gôndola, Katakombe e Galeria Dezon (Copacabana)... e até em Petrópolis (: 17).

Com base nessa idéia de Jaguar, pode-se pensar que a categoria "Ipanema", pensada como um adjetivo que qualifica pessoas, lugares e comportamentos, não precisa estar necessariamente vinculada ao espaço físico do bairro. Da mesma forma, "ipanemense" ou "ipanemenho" são identidades utilizadas para designar pessoas que não têm, necessariamente, um vínculo direto com os limites territoriais de Ipanema. Morar no bairro, por exemplo, não é uma condição necessária, nem tampouco suficiente, para que um indivíduo assuma essa identidade. De modo análogo, "ipanemenses típicos" podem ser habitantes de outras localidades, como é o caso do próprio Jaguar:

Nós, ipanemenses dos anos 60, estávamos nos lixando para os limites geográficos do bairro. Eu mesmo, enchendo a boca falando em "nós, ipanemenses", morava em Copacabana.... Havia uma espécie de imperialismo ipanemense. Como grileiros, invadíamos a cidade e até o estado do Rio (: 17).

$\mathrm{Na}$ obra de Ruy Castro essa idéia também é marcante já que nem todas as personalidades que aparecem em seu livro foram moradoras de Ipanema. Exemplos paradigmáticos da "autonomia" que esse conjunto de representaçóes apresenta diante das fronteiras do bairro são os artistas internacionais que aparecem na enciclopédia desse autor.

Um verbete interessante é o de Isadora Duncan, que esteve de passagem pelo Rio de Janeiro, em 1915, na seqüência de uma turnê mundial. Percebe-se que o que explica a presença dessa dançarina na "enciclopédia de Ipanema" não é somente o fato da artista ter conhecido a praia do Arpoador durante sua estadia na cidade, mas a percepção de que seu "perfil" assemelha-se ao da típica mulher ipanemense, defendido por Ruy Castro. O autor descreve Isadora Duncan como "uma modernista radical, na dança e no comportamento: escolhia os homens que queria como amantes, tinha filhos com eles, dispensava-os de casar e aonde fosse, arrastava séquitos de todos os sexos" (: 174). Aqui, o bairro é associado não ao imaginário "boêmio", mas às noções de "ousadia" e "liberdade", que também são empregadas na descrição de quase todas as mulheres da enciclopédia. A percepçáo de que as ipanemenses teriam uma inclinação para romper com os papéis de gênero convencionalmente prescritos aparece no seguinte trecho:

As mulheres de Ipanema tinham desprezo por conceitos como virgindade, casamento burguês, 
fritar bolinhos, monogamia e maridinho-provedor-do-lar. Elas estudavam, trabalhavam, moravam sozinhas, namoravam quem quisessem e não davam satisfaçóes. Nada que fizessem era chocante em Ipanema (: 210).

Ao qualificar como "ipanemenses" a americana Isadora Duncan e as festas na Praça Tiradentes e em Santa Tereza, Ruy Castro e Jaguar sugerem que os aspectos simbólicos atribuídos à Ipanema transcendem os limites territoriais do bairro. Ao contrário do que pode parecer, esse aspecto somente comprova a importância do espaço para a criação de classificaçóes sociais. Como sugeriu Mauss (1974) - ao pesquisar a sociedade esquimó - e Halbwachs (1990) - ao refletir sobre o tema da memória - o espaço é uma categoria de pensamento que estrutura representaçóes e práticas sociais. Assim, embora o imaginário sobre Ipanema seja sólido o suficiente a ponto de se desligar das fronteiras do bairro, é somente em referência àquele espaço que esse conjunto de representaçóes e de memórias se consolida, adquirindo sentido.

São muitas as representaçóes evocadas pela palavra "Ipanema", podendo designar tanto estilos de vida "livres", "transgressores" e "modernos" quanto "boêmios", "criativos" e "informais". De uma maneira ou de outra, "Ipanema" é uma categoria repleta de significados, e vale a pena pensar que, se por um lado, essas elaboraçóes são utilizadas para enaltecer o bairro, por outro, elas também podem assumir valores negativos e transformar a identidade "ipanemense" em uma categoria de acusação.

Para compreender de que modo "Ipanema" simbolizou um rótulo negativo é interessante buscar alguns emblemas capazes de traduzir aquilo que se considera como o "espírito" do bairro em épocas passadas. Dentre todas as personalidades, acontecimentos e lugares recorrentemente citados nos livros e na imprensa, acredito que a atriz Leila Diniz e o jornal $O$
Pasquim podem ser "bons para pensar" um tipo de representação atribuído à Ipanema contra o qual voltaram-se alguns discursos acusatórios.

A associação entre Leila Diniz e o passado de Ipanema é evidente. A atriz integrava a "turma de Ipanema” de que falam Jaguar e Carlos Leonam, e na enciclopédia de Ruy Castro sua descrição possui um número de páginas superior ao da grande maioria dos demais verbetes. A imprensa também sustenta que "poucas mulheres encarnaram tão bem o espírito de Ipanema. Bem-humorada, curiosa, transgressora, Leila Diniz foi a grande musa do bairro." (Veja Rio: 13). Na célebre entrevista ao jornal O Pasquim, comenta Goldenberg (1995), Leila Diniz transgrediu as regras de linguagem, negou os principais valores do campo artístico afirmando que escolhia o trabalho pela "patota" e pela diversão e mostrou viver sua sexualidade de forma livre e intensa. A fotografia de sua gravidez de biquíni amplamente divulgada pela imprensa da época (e de hoje também) simbolizou a transgressão em relação aos usos do corpo feminino, além de trazer para a polêmica a rejeição da atriz pelo casamento convencional e pelos papéis tradicionais de "ser mulher". Assim, se a figura de Leila Diniz é apropriada pelos meios de comunicação para exemplificar o "tipo ideal" ipanemense, isso se deve, em grande medida, pelo fato de a atriz ter demonstrado publicamente sua recusa a uma série de valores predominantes na sociedade brasileira das décadas de 1960 e 1970.

A partir das acusaçóes que recaíram sobre os comportamentos dessa atriz, é possível pensar sobre o modo como a identidade "ipanemense" foi vivenciada como um rótulo negativo. $\mathrm{O}$ trabalho de Goldenberg (1995) mostra que as acusaçóes de desvio variam conforme o grupo que cria o rótulo. Enquanto Leila foi chamada de "puta" e de "subversiva" pela "direita", a "esquerda" e as feministas da época acusavam-na de ser "alienada", "superficial" e "porra-louca". 
Outro ícone do passado de Ipanema capaz de colaborar para o entendimento das acusaçóes de desvio é o jornal $O$ Pasquim. Vale dizer que os três autores aqui analisados - Jaguar, Carlos Leonam e Ruy Castro - já trabalharam ou, pelo menos, colaboraram com esse semanário. Em fins de 1970, nove integrantes de O Pasquim foram presos pelo governo militar e o jornal foi mantido sob censura. $\mathrm{Na}$ enciclopédia ipanemense, Ruy Castro defende que o jornal era "engraçado, provocativo e desrespeitoso, mesmo quando tratava de assuntos sérios" (: 281) e faz ressalvas ao classificá-lo como um jornal de oposição:

Nitidamente era um jornal "de esquerda" - mas não da esquerda oficial, do Partidão... ou mesmo da esquerda estudantil, maoísta, que já começara a assaltar bancos e a fazer caixa para a luta armada. Era uma esquerda de humoristas, mais para festiva, tipo Ipanema, que os militares ainda não levavam a sério (: 280).

Era o apogeu da Esquerda festiva, da qual o Pasquim era um alegre porta-voz, e do mito de Ipanema, de que ele foi o grande estimulador (: 282).

No livro Os degraus de Ipanema, Carlos Leonam mostra que as críticas dirigidas aos ipanemenses eram uma preocupaçáo para Jaguar, fundador d'O Pasquim, nas primeiras tiragens do jornal. Em resposta ao pedido de Carlos Leonam para colaborar com o tablóide, Jaguar teria advertido: "queremos fazer um jornal que não seja rotulado de ipanemenho" (: 218). Segundo Braga (1991: 193), uma acusação freqüente que se fez a $O$ Pasquim é que, apesar de crítico e politicamente avançado, o jornal era machista. De acordo com o autor, embora O Pasquim abrisse espaço para artigos escritos por colaboradoras que participavam das lutas da mulher, ele também ironizava as feministas mais engajadas em algumas frases de capa como "Pasquim - um jornal ao lado da mulher. E se for o caso, sobre e sob"; "Pasquim - Um jornal por dentro das feministas" ou "Desculpe Dona Betty [Friedan], mas nós vamos dar cobertura às furadoras da greve do sexo".

Se Ipanema representava, de um lado, uma "ameaça" ao governo militar por ter sido, segundo Ruy Castro, "um reduto permanente de oposição que combateu ou criticou todos os governos dos últimos sessenta anos" (: 11), muitas acusaçóes dirigiam-se, por outro, à postura excessivamente "descontraída" e à falta de compromisso e seriedade dos ipanemenses frente às questóes mais "importantes" do país. Talvez seja em referência a esses aspectos que o autor comenta a condenação da cantora Nara Leão à “alienação de Ipanema” (: 59).

As acusaçóes dirigidas a $O$ Pasquim e à atriz Leila Diniz variaram conforme grupos sociais distintos. De um lado, sofreram perseguiçóes por representarem uma ameaça à ideologia do governo militar; eram considerados "perigosos" pelos segmentos mais conservadores da sociedade brasileira da década de 1960. De outro, aos olhos dos militantes políticos de oposição ou das lutas feministas, esses ícones de Ipanema simbolizavam o "desbunde", a falta de seriedade e a alienação. Sob esse aspecto, os ipanemenses típicos ocupavam uma posição peculiar em um sistema de rotulaçáo e de acusaçáo. A ameaça apresentada por esses jovens resultava de uma condição que oscila entre pólos antagônicos, como o de "subversivo", de um lado, e o de "alienado", de outro. Estes exemplos mostram de forma paradigmática a idéia de Becker (1971) segundo a qual não existem condutas essencialmente desviantes, mas diferentes maneiras de se reagir a elas. Para o autor, o desvio náo é criado por aquele que o realiza mas pelos grupos que o classificam como desviante.

\section{A Ipanema do presente}

Os autores aqui investigados sugerem que Ipanema não é mais como antes pois os locais 
e acontecimentos mais representativos de suas memórias, como os bares, a praia e a Banda de Ipanema perderam o seu caráter distintivo e "autêntico". Sob o ponto de vista de Jaguar e de Carlos Leonam, Ipanema é "aquela Ipanema”, ou seja, o bairro que marcou os "anos gloriosos" de sua geração. Já o material de imprensa, embora também celebre o passado de Ipanema, apresenta uma versão mais positiva sobre o bairro. Ipanema teria adquirido, segundo os jornais e revistas, novos atributos igualmente valorizados. Os maiores responsáveis por emprestar um novo caráter ao bairro teriam sido os serviços de alto luxo inaugurados nos últimos anos em Ipanema. Esta idéia pode ser vista nos três suplementos pesquisados:

Tudo está muito distante da velha Feira Hippie que marcou os anos loucos do bairro. O comércio sofisticou-se para atender uma rica clientela de várias partes do mundo....Ipanema se profissionalizou... A maioria dos velhos casaróes do bairro já não existe mais. Eles deram lugar a hotéis de luxo, edifícios comerciais modernos e inteligentes ou a condomínios residenciais sofisticados (Jornal do Brasil: 4).

Além de uma volta ao passado, este especial do Globo-zona sul revela que a história do bairro, da qual fazem parte Tom Jobim e Vinícius de Moraes, continua sendo escrita, hoje, por empresários da moda que, sediados em Ipanema, exportam seu estilo de vida ( $O$ Globo: 16).

Nas últimas décadas, enquanto os saudosistas lamentavam o fim do agito cultural que marcou o bairro dos anos 40 aos 70, estilistas, designers e restaurateurs foram, aos poucos, mostrando mais uma vocação de Ipanema... o bairro hoje é o mais luxuoso shopping a céu aberto da cidade. É também praia de modismos e corpos esculturais, mesa de inovaçôes gastronômicas, vitrine de roupas e acessórios impecáveis (Veja Rio: 11).
A Ipanema atual é retratada pela imprensa por meio das categorias "luxo", "charme" e "sofisticação". Essas noções ganham contornos mais específicos quando se observam quais são as localidades percebidas como "luxuosas" e "sofisticadas". O Caderno H do Jornal do Brasil, por exemplo, fundamenta o "glamour" de Ipanema quando ressalta que no bairro "estão reunidas as joalherias mais sofisticadas do mundo como Amsterdam Sauer, H. Stern, Mont Blanc, Cartier...” (: 4). Os restaurantes, as livrarias e algumas lojas também aparecem como exemplos do caráter "moderno" e "requintado" da região. A importância conferida a esse novo comércio para a nova feição do bairro se manifesta através da freqüência com que os proprietários ou representantes desses locais são solicitados pela imprensa. As matérias abrem espaço para os indivíduos dessa categoria justificarem suas escolhas por Ipanema, e eles argumentam tratar-se de um local estratégico:

\footnotetext{
'Hoje Ipanema é fundamental para projetar uma marca no país e internacionalmente. Como a Rua Oscar Freire em São Paulo', explica o estilista Tufi Duek, que inaugura na terça uma megaloja da sua Forum na Praça Nossa Senhora da Paz (Veja Rio: 14).
}

O prestígio conquistado por esse grupo envolvido com o novo comércio do bairro é tal que eles são solicitados não apenas para discutirem o caráter rentável ou promissor de Ipanema, mas também para revelarem suas opinióes pessoais sobre o bairro:

'Minha mulher está sempre descobrindo coisas fantásticas por aqui', conta Rui Campos, o Rui da Livraria da Travessa.... 'A gastronomia é hoje, sem dúvida, um dos trunfos de Ipanema’ diz Angela Hall, gerente da Louis Vuitton e moradora do bairro... 'É um bairro cheio de vida', afirma a arquiteta Bel Lobo, que deu forma a 
vários restaurantes e lojas da regiáo... (Veja Rio: 15-16).

Não é difícil imaginar que a imprensa demonstre outros interesses - para além da comemoraçáo do aniversário de 110 anos - para elaborar uma imagem positiva sobre Ipanema. Seria ingênuo desconsiderar os interesses econômicos dos meios de comunicação nos empresários atuantes no bairro. Nesse sentido, é possível pensar que muitas matérias acabam cumprindo uma função publicitária que visa tornar mais atrativos os serviços dos anunciantes por meio de uma exaltação do bairro onde estes se localizam. De qualquer maneira, é possível refletir que se o passado do bairro - conforme expressam os livros - é elaborado por uma elite intelectual que se coloca como protagonista das memórias do bairro, a atualidade de Ipanema - como revela a imprensa - é elaborada por uma elite comercial que também se inclui com destaque nas representaçóes simbólicas desse bairro. Pode-se sugerir que os critérios que tornam determinadas pessoas "legítimas" para falar sobre Ipanema variam segundo o recorte temporal que se pretende abordar. Enquanto os portadores das "memórias autênticas" ou do relato mais "confiável" sobre o passado são artistas e intelectuais, a hierarquia de credibilidade (Becker, 1977) se transforma quando o tema é a atualidade, em que os indivíduos que ganham maior legitimidade são os representantes do comércio de luxo.

Dentre os profissionais ligados ao campo da moda e da gastronomia, há dois indivíduos que merecem atenção por receberem destaque nos três suplementos analisados. São eles, Oskar Metsavaht e Alexandre Accioly. O primeiro é proprietário da cadeia de lojas Osklen, grife que vende roupas para um público jovem de classe média/alta. Já o segundo é sócio de quatro restaurantes de elevado padrão relativamente recentes no bairro. Ambos são descritos como fortes investidores na região:
Ipanema firma-se como endereço predileto das grifes e atrai novos investidores. Entre eles, Oskar Metsavaht, dono da Osklen há 15 anos, que há apenas dois abriu a primeira loja no local: - "Ipanema foi o bairro que escolhi para fincar a primeira loja internacional da Osklen..." (O Globo: 18).

Alexandre Accioly, capa deste $\mathrm{H}$, acredita em Ipanema. Ele é seguramente quem mais investe no bairro nos últimos anos... Somando tudo, são US\$ 12 milhóes jogados no pano verde que hoje se tornou investir no Brasil (Jornal do Brasil: 11).

Não é apenas a imagem de "proprietários de negócios" que torna curiosa a aparição desses dois indivíduos na imprensa. Accioly e Metsavaht parecem "corporificar" um tipo de representação sobre o bairro. Nas fotografias e em alguns trechos presentes nessas matérias, os hábitos e as preferências de ambos, como a prática de esportes ao ar livre, são descritos por meio de uma relação estreita com os espaços do bairro. A praia de Ipanema, por exemplo, é representativa de seus hábitos cotidianos, servindo inclusive como o cenário de quase todas as fotografias em que os dois aparecem nos jornais. A relação de Accioly com a praia surge na descrição de sua trajetória como morador do bairro desde a infância:

Pedra do Arpoador, o point de suas tardes, onde [Accioly] curtia o pôr-do-sol... Adulto, transferiu-se para a rede de vôlei em frente ao Country, onde dava plantão nos fins de semana. Das nove até a noitinha' (Jornal do Brasil: 11).

Esse empresário foi eleito "O garotão de Ipanema", aparecendo em uma enorme fotografia de capa do Caderno H. Alto, de pele bronzeada e aparência jovial, o empresário está vestido com camisa social, calças compridas e chinelo, sentado à noite no calçadáo da praia de Ipanema. 
Essa mistura de elegância com informalidade também é transmitida na foto do interior $\mathrm{da}$ matéria, onde Accioly está de trajes "sociais", tomando água de coco mas com os pés descalços na praia. O texto localizado abaixo diz: "Coco verde, areia no pé e o privilégio de ser, desde sempre, um garoto de Ipanema" (: 11). Outra matéria ressalta que Accioly vive no edifício Cap Ferrat, "supra-sumo do luxo à beira-mar, onde não se compra um imóvel por menos de 3,5 milhôes de dólares" (Veja Rio: 15).

De modo semelhante, Oskar Metsavaht aparece no Caderno Zona Sul do jornal $O$ Globo com a praia ao fundo, vestindo uma camiseta que diz "United Kingdom of Ipanema". Seu depoimento é colocado em destaque abaixo dessa fotografia: "Ipanema é muito privilegiada, com uma vida cosmopolita integrada à natureza” (: 20). Essa mesma opinião está presente na Veja Rio, que dedicou um trecho da reportagem para a apresentação das atividades físicas realizadas por Metsavaht em Ipanema:

"O bairro simboliza uma vida urbana integrada com a natureza, o que náo existe em nenhum lugar do mundo", diz o estilista gaúcho Oskar Metsavaht, que há vinte anos mora, surfa, corre, pedala e anda de skate no bairro. (Veja Rio: 16).

A idéia de que Ipanema é um bairro de pessoas "jovens", "ricas" e "descoladas" também está implícita na escolha de suas atuais musas. Esse bairro está fortemente associado a uma dimensão lúdica que se constrói por meio de uma exaltação de elementos "naturais". A praia, o mar, os coqueiros e a pedra do Arpoador, por exemplo, são símbolos que associam o bairro à idéia de beleza. Insistindo na percepção de um contágio entre espaço e pessoas, Ipanema é percebida como um local que produz pessoas belas, sobretudo, mulheres. Na medida em que o imaginário do bairro sofre transformaçôes com o passar dos anos, o perfil das musas de Ipanema também se modifica. Se Leila Diniz foi considerada musa do bairro na década de 1960, a imprensa atual elege a apresentadora de um programa televisivo de esportes como um ícone da Ipanema de hoje. Cíntia Howlett já foi eleita "musa do verão" e é lembrada por habitar em uma localização de prestígio em Ipanema; em um edifício de frente para a praia do Arpoador. Fotos ou depoimentos ligados a essa ipanemense são recorrentes em matérias sobre Ipanema:

Entre os rostos manjados de Ipanema está a apresentadora Cíntia Howlett, moradora do Arpoador. Geração saúde, Cíntia corre no calçadão, nada, anda de bicicleta na ciclovia. "Minha ginástica é Ipanema, e isso não tem preço”, observa. (Veja Rio: 16)

Assim como os emblemas masculinos anteriormente citados, Cíntia Howlett também representa uma dimensão "nobre" combinada a um estilo de vida "despojado", “jovem" e "esportivo". No suplemento da revista Veja, outras mulheres são assim percebidas na matéria de página dupla "Ipanema, uma jovem de 110 anos". $\mathrm{Na}$ página direita, a fotografia revela uma mulher branca, jovem, cabelos lisos, de óculos escuros, caminhando na calçada da Rua Visconde de Pirajá: "A estilista Joana Saladini: compras a pé pelas ruas do bairro" (: 11). Na outra página há uma garota de short e biquíni na praia com a seguinte descrição "A wakeboarder Juliana na Praia de Ipanema: beleza no Posto $10 . .$. corpo moldado pelo treino de wakeboard" (: 10-13). Segundo a matéria, as duas moças de Ipanema "não hesitam em apontar o mesmo passatempo para as horas vagas: bater perna de olho nas vitrines que se espalham pelas ruas dali" (: 13).

Assim como um único ipanemense pode reunir as diferentes características atribuídas ao bairro, o estilo de vida "descontraído" e "requintado" também pode ser identificado em uma 
IPANEMA E SUAS MODAS: PASSADO X PRESENTE 59

mesma localidade. O Caderno Zona Sul destaca que os restaurantes com varandas e mesas na calçada se multiplicaram em Ipanema nos últimos anos e sugere que "sem perder a descontração da cidade praiana, eles têm o típico requinte ipanemense"(: 45). A Veja Rio destaca o "almoço na varanda" e a "vida saudável à beira mar" como programas típicos de Ipanema: "além da vida saudável à beira-mar, programa em Ipanema é o footing pelas ruas aos sábados, compras todos os dias, almoços na varanda do Gula Gula, cineminha no Estação" (Veja Rio: 16).

A categoria "Ipanema", tal como é transmitida pelos jornais e revistas, parece representar algo mais do que o espaço geográfico de um bairro. Ela denota, acima de tudo, um estilo de vida. A descrição de personalidades como Oscar Metsavaht, Alexandre Accioly e Cíntia Howlett é apenas uma maneira de expressar algumas das representaçóes associadas ao bairro, como a de um lugar informal, com belezas naturais, propício para os esportes e, ao mesmo tempo, urbano, de elevado padrão e sofisticado. Essa junção de atributos se transfere para os indivíduos do bairro. Ipanema teria produzido pessoas que assumem um estilo de vida "esportivo" e "espontâneo" sem deixarem de ser "elegantes" e "cosmopolitas".

Para tornar essas representaçóes mais concretas, vale mencionar a estratégia do estilista Oskar Metsavaht em explorar comercialmente esse imaginário através da criação de uma identidade "ipanemense" para sua grife de roupas Osklen. Vale lembrar que mesmo antes da instalação da Osklen de Ipanema, a marca, voltada para um público de elite, já era identificada com as idéias de valores como "juventude", "esportes" e "natureza". Com a chegada à Ipanema, a estratégia de marketing parece ter sido a de reforçar esses conceitos associando a Osklen a um estilo de vida típico "de Ipanema":
Ipanema é admirada no mundo inteiro e tem uma condição privilegiada com uma vida urbana cosmopolita integrada à natureza - diz Metsavaht, que estampou "Arpoador" e "Posto 9" em blusas da última coleção da Osklen e criou a campanha "United Kingdom of Ipanema", que dá a dimensão do quanto ele gosta do bairro $(O$ Globo: 20).

Através dessa "jogada” publicitária nota-se que o bairro de Ipanema também se apresenta sob a forma de um bem de consumo. O que se vende na Osklen não são simples camisetas, mas um estilo de vida "ipanemense" que é socialmente valorizado.

\section{Dois bairros, duas moralidades}

A partir da análise sobre os livros e as matérias de imprensa observou-se que, mais do que um território espacial, Ipanema é pensada como um adjetivo capaz de qualificar pessoas, comportamentos e estilos de vida. De uma visáo de mundo orientada para a vanguarda comportamental, a criatividade artística e a boemia, o bairro passou a simbolizar uma dimensão "de elite", inclinada para o consumo e para as atividades físicas.

Notou-se, portanto, a elaboração de duas Ipanemas; uma do passado e outra do presente. Enquanto a primeira é caracterizada como um bairro "transgressor", que "lançou modas", a Ipanema atual é um local "sofisticado" e "descolado”. Essas duas construçôes simbólicas se elaboram por meio de uma associaçáo entre espaços e indivíduos, evidenciando-se através de uma mudança nas personalidades e nos locais tidos como emblemáticos do bairro. Se os ipanemenses do passado são artistas, cineastas e músicos, os de hoje são empresários, estilistas e esportistas. Enquanto os bares representaram o "espírito ipanemense" do passado, as joalherias, os restaurantes e as grifes de roupa definem o "espírito atual" desse bairro. 
Para ilustrar essas variações de imaginário é interessante refletir sobre o perfil das musas e sua relação com o principal espaço do bairro; a praia. Foi na praia que a musa de Ipanema na década de 1960 - Leila Diniz - ficou publicamente conhecida por seu comportamento "transgressor". As musas atuais de Ipanema percebem a praia como o local da "ginástica" e dos "esportes". Se a praia "de antes" simbolizou o espaço da "transgressão" às normas, onde o corpo ipanemense se apresentou de modo "polêmico" e "livre", a praia de hoje é o local das atividades físicas, da moralidade da boa forma onde o corpo valorizado é "trabalhado", "saudável” ou "sarado" (Goldenberg 2002).

Esta pesquisa permitiu pensar sobre algumas mudanças sociais dos últimos quarenta anos na medida em que os valores utilizados para enaltecer um bairro emblemático da cidade do Rio de Janeiro tornaram-se quase antagônicos. Embora permaneça a noção de um bairro lúdico, "bonito por natureza" e propício para um estilo de vida "descontraído" e "informal", pode-se pensar em uma mudança de atitude frente às normas socialmente prescritas. $\mathrm{O}$ significado de Ipanema como um bairro peculiar da cidade do Rio de Janeiro na década de 1960 foi construído por uma exaltaçáo de aspectos contestadores e transgressores, como a liberação do corpo e da sexualidade, a arte de vanguarda e a boemia. De modo contrário, esse bairro é atualmente celebrado por representar uma conformidade com os valores predominantes, como a produtividade, a riqueza, o consumo, o corpo saudável e estético.

\section{Referências bibliográficas}

BECKER, Howard. 1971. Los Extraños: sociología de la desviación. Buenos Aires: Tiempo Contemporáneo.

1977. “De que lado estamos?”. In Uma teoria da ação coletiva. Rio de Janeiro: Zahar.

BRAGA, J.L. 1991. O Pasquim e os anos 70. Brasília: UnB.

DAMATTA, Roberto. 1978. "O ofício de etnólogo, ou como ter 'anthropological blues". In A aventura sociológica. Rio de Janeiro: Zahar.

1998. Nobres e Anjos: um estudo sobre tóxicos e hierarquia. Rio de Janeiro: Fundação Getúlio Vargas.

GOLDENBERG, Míriam. 1995. Toda Mulher é meio Leila Diniz. Rio de Janeiro: Record.

2002. Nu \& Vestido. Rio de Janeiro: Record.

HALBWACHS, Maurice. 1999. A memória coletiva. São Paulo: Vértice.

MAUSS, Marcel. 1974. "Ensaio sobre as variações sazoneiras das sociedades esquimó". In Sociologia e Antropologia. São Paulo: EPU/EDUSP (v. 2).

SIMMEL, George. 1988. "La moda". In Sobre la aventura. Barcelona: Editora Península.

VELHO, Gilberto. 1978. A utopia urbana: um estudo de antropologia social. Rio de Janeiro: Zahar.

\section{Fontes de Pesquisa}

CASTRO, Ruy. 1999. Ela é Carioca: uma enciclopédia de Ipanema. São Paulo: Companhia das Letras.

JAGUAR. 2000. Ipanema, se não me falha a memória. Rio de Janeiro: Relume Dumará.

LEONAN, Carlos. 1997. Os degraus de Ipanema. Rio de Janeiro: Record.

"Ipanema, 110 anos na vanguarda". 22.abr.2004. Caderno Zona Sul. $O$ Globo.

"O garotão de Ipanema - Ipanema 110 anos, edição especial”. 25.abr.2004. Caderno H. Jornal do Brasil.

"Ipanema 110 anos: Histórias e personagens do bairro mais charmoso da cidade”. 26 abr. 2004-02 maio 2004. Veja Rio. 